\title{
Study of gas consumption patterns for sheet glass enterprises
}

\author{
Yauhen Shenets ${ }^{1, *}$, Deniz Moroz $^{2}$, Nadzeya Hruntovich $^{3}$, Mikhail Malashanka $^{4}$, and Alexei Tsvetkov $^{5}$ \\ ${ }^{1}$ Public corporation "Gazprom transgaz Belarus" Nekrasova 9, Minsk, Republic of Belarus \\ ${ }^{2}$ State Enterprise "Research Institute Belgiprotopgaz", Domashevskij lane,11a, Minsk, Republic of Belarus \\ ${ }^{3}$ Sukhoi State Technical University of Gomel, Prospect Octiabria, 48, 246746, Gomel, Republic of Belarus \\ ${ }^{4}$ Energy Efficiency Department of the State Committee for Standardization of the Republic of Belarus, Minsk, Svobody sq. 17, 220030, \\ Republic of Belarus \\ ${ }^{5}$ Kazan State Power Engineering University, str. Krasnoselskaya, 51, 420066, Kazan, Russia
}

\begin{abstract}
A study of the gas consumption modes of the subgroup "Enterprises of construction industry and architecture" of the regional gas supply system, as well as the production of sheet glass, which forms gas consumption in the subgroup by $94 \%$, was carried out. The field type "daily gas consumption - outside temperature" is set for the subgroup and the plant for production of sheet glass. This is a field with a weak dependence on the growth of daily gas consumption when outside temperature decreases and without an obvious stratification into temperature regions determined by the state of the heating system ("on" or "off") and a significant vertical spread of daily gas flow at the same values of outside temperature. Additional factors affecting gas consumption were searched. The created database of 14 technological indicators over a seven-year period allowed to identify factors forming daily and annual gas consumption regimes using correlation-regression analysis. The importance of the "time worked by the line" factor and its contribution to the formation of the annual volume of gas consumption was assessed. Invention proposes a simplified method of estimating the rate of aging of furnace lining and wear of enclosing structures on the basis of a single-factor model of gas consumption from productivity by comparing the daily average annual values of specific gas consumption for sheet glass production with the same volume of output.
\end{abstract}

\section{Introduction}

Many years of world experience show that during the operation of furnace equipment (glass, cement enterprises) the furnace lining is burned and the enclosure structures of the furnace body are worn, as a result of which more gas is spent to compensate for losses and maintain the parameters of melting modes [1, $2,3]$. A quantitative indicator of the deterioration of the furnace lining of the sheet glass plants is the increase in the specific gas consumption $(S G C)$ for the production of 1 ton of production $\left(B_{\mathrm{SGC}}\right.$, tons of fuel equivalent/tons next $B_{\mathrm{SGC}}, \mathrm{t}$ f.e./tons). For the world 's leading glass industry enterprises of Germany, Canada, the USA, the warranty and depreciation life of furnace equipment is 56 years [4, 5]. Good quality of furnace design, construction and maintenance allows to bring the life of the furnace to 10-12 years [6], and in some cases more, with acceptable reduction of energy efficiency (EE) [7]. At the end of this period, the morally obsolete furnace must be dismantled and replaced with a new one. During the operation of the furnace, its scheduled hot and cold repairs are carried out with further adjustment of melting process parameters, which allows to contain the rate of EE fall (growth of specific gas consumption per production unit output) in accordance with the approaches $[8,9$ and 10]. In order to make a natural gas application, enterprises with gas furnaces in their process equipment must take into account the factor of "furnace lining burnout and wear of enclosing structures," as its disregard can lead to a significant error in the declared volume of gas even when the volume of output is maintained.

\section{Methodology}

According to [11] gas industry enterprises are concerned with studying the structure and regularities of regional gas supply systems functioning, as well as the regularity of natural gas consumption, their planning in different sectors of the economy. Glass industry enterprises are part of the structure of the subgroup "Enterprises of construction industry and architecture" of the enlarged balance group "Industry" of the regional gas supply system. The share of enterprises of this subgroup in the gas consumption of the of the region's industry is from 15 to $21.8 \%$ for $2012-2017$. The subgroup consists of 17 balance structural elements - construction organizations, enterprises for the production of construction materials and enterprises for the production of sheet glass. At the first stage of studies of the patterns of formation of gas consumption modes, coefficients of paired correlation between the daily gas flow rate $\left(B_{d a y}\right)$ and the average daily outside temperature $\left(t_{d a v}\right)$ were calculated, which

Corresponding author: shenets@mail.ru 
for different years amounted to: $2012--0.86 ; 2013-$ $0.18 ; 2014--0.58 ; 2015--0.72 ; 2016--0.59 ; 2017-$ 0.53 . The resulting correlation coefficient values indicate an unstable (from low to average) relationship between temperature and daily gas flow rate and require the search for additional factors affecting gas consumption. And the built structural fields over a six-year period made it possible to establish a type of field with dependence of daily gas consumption growth with reduction of outside temperature without obvious stratification into temperature areas determined by the state of the heating system ("on" or "off"), with significant vertical spread of $B_{d a y}$ at the same values of outside temperature (Figure 1). In 2013, a day with low $B_{\text {day }}$ consumption is allocated from the total daily gas consumption pattern, which may be related to the shutdown of a powerful process plant.

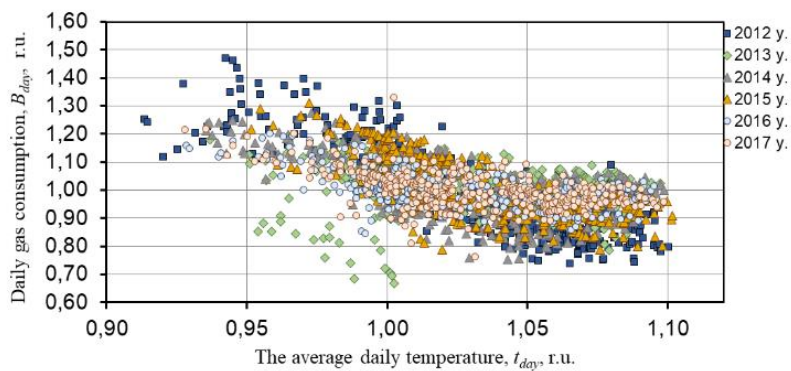

Fig. 1. Structural field "daily gas consumption - temperature" of the subgroup "Enterprises of construction industry and architecture" of the regional gas supply system.

The sheet glass production plant, which is part of the sub-group under consideration, forms $94 \%$ of its total natural gas consumption. The production of sheet glass as a consumer of energy resources is characterized by the complex nature of the relationship between energy and technology, when energy consumption is influenced by many technological factors. In order to identify and account for the factors that form the mode of gas consumption, an information database for 7 years has been formed, containing information on 14 technological indicators, such as the daily consumption of natural gas, $B_{d a y}$, thousand $\mathrm{m}^{3}$; average daily caloric content of natural gas, $\mathrm{kcal} / \mathrm{m}^{3}$; daily electricity consumption; average daily productivity of the furnace, $\mathrm{P}, \mathrm{t} /$ day; glass thickness, mm; density of glass, $\mathrm{p}, \mathrm{t} / \mathrm{m}^{3}$; average daily outside temperature, ${ }^{\circ} \mathrm{C} ; \mathrm{FeO}$ content in glass, $\% ; \mathrm{Fe}_{2} \mathrm{O}_{3}$ content in glass, \%; $\mathrm{Fe}_{2} \mathrm{O}_{3}$ content in sand, \%; $\mathrm{Fe}_{2} \mathrm{O}_{3}$ content in dolomite, $\%$; ratio of charge to broken glass, $\%$; humidity of charge, $\%$; number of days of furnace operation, $\mathrm{N}$, days. It was found that there was no strong relationship (multicollinearity) between the factors included in the model.

For the first time it is proposed to introduce the factor "number of days of furnace operation" to build a multifactor model of gas consumption. Further studies have shown that this has made it possible to estimate the aging rate of technological equipment and the associated increase in the volume of gas consumed.

Table 1 shows regression analysis results for significant parameters over a six-year period of operation and regression coefficient values for each parameter.

Table 1. Results of mathematical modeling after excluding insignificant factors.

\begin{tabular}{|c|c|c|c|}
\hline $\begin{array}{c}\text { Technological } \\
\text { parameter (model } \\
\text { factor) }\end{array}$ & $\begin{array}{c}\text { Regression } \\
\text { coefficients }\end{array}$ & $\begin{array}{c}\text { Standard } \\
\text { error }\end{array}$ & $\begin{array}{c}\mathrm{t}- \\
\text { statistics }\end{array}$ \\
\hline $\begin{array}{c}\text { Productivity, } \mathrm{P}, \\
\text { tons/day }\end{array}$ & 163.5 & 1.67 & 97.7 \\
\hline $\begin{array}{c}\text { The outside } \\
\text { temperature, }{ }^{\circ} \mathrm{C}\end{array}$ & 157.7 & 9.69 & 16.2 \\
\hline $\begin{array}{c}\text { The content of } \mathrm{FeO} \\
\text { in the glass, \% }\end{array}$ & 805488.16 & 42592.93 & 18.9 \\
\hline $\begin{array}{c}\text { Number of days of } \\
\text { furnace operation, } \\
\text { day }\end{array}$ & 14.58 & 0.203 & 71.6 \\
\hline
\end{tabular}

Table 1 shows that after reducing the number of factors (elimination of statistically insignificant model factors) included in the model, the values of the Student's t-distribution (t-statistics) for each parameter exceed the critical value, which indicates the statistical significance of certain parameters for the task of determining the EE of the enterprise.

Thus, the resulting multi-factor model of daily gas consumption in the production of sheet glass is described by the dependence:

$$
\begin{aligned}
& B_{t f . e}=F\left(P, t_{o}, F, N\right)=163.5 \cdot P+ \\
& +157.7 \cdot t_{o}+805488.2 \cdot F+14.6 \cdot N
\end{aligned}
$$

Where:

$P$ - productivity, t/day;

$t_{o}$ - outside temperature, ${ }^{\circ} \mathrm{C}$;

$F$ - content of iron oxide in glass, $\%$;

$N$ - number of days of furnace operation, day.

Description of the statistically significant factors of the model:

i. The regression coefficient before the factor «performance» is 163.5. This means that every day 163.5 kilogram of fuel equivalent (next $-\mathrm{kg}$. f.e.) of natural gas is spent on the technological process of glass production for the production of 1 ton of glass.

ii. The regression coefficient before the factor "outside temperature" is 157.7. This means that the $1^{\circ} \mathrm{C}$ change in outside temperature for the glass manufacturing process results in an average change in the daily natural gas flow rate of $157.7 \mathrm{~kg}$. f.e.. This dependence is explained by the operating conditions of the furnace in the summer (hot) period of the year, when to prevent accelerated destruction of the outer lining of the furnace, it is cooled using technological ventilation units. To compensate for this additional heat loss and maintain the process of glass formation in the furnace pool with a given temperature, an additional supply of fuel gas to the furnace burners is provided.

iii. The regression coefficient before a factor "FeO content" (iron oxide content in glass) makes 805488.3. This means that for the technological process of glass production, a change in the content of iron oxide in glass by $1 \%$ leads to a change in the daily 
consumption of natural gas by $805488.3 \mathrm{~kg}$. f.e.. This dependence is explained by the process of glass formation in the course of redox reaction in the glass production furnace by float method, which is based on achieving the state of equilibrium of iron ions with different degree of oxidation of $\mathrm{Fe}^{2+}$ and $\mathrm{Fe}^{3+}$ in the glass paste [12] and is based on control of temperature mode inside the furnace by adjustment in supply of fuel gas and supply of a certain portion of oxygen.

iv. Regression coefficient before factor "number of days of furnace operation" is 14.5. This means that the daily consumption of natural gas for glass production increases by $14.5 \mathrm{~kg}$. f.e.. Taking into account the generally accepted type of consumption models of fuel and energy resources, the factor "number of days of furnace operation" is presented as a conditional-constant component of the model due to constant and stable loading of the furnace 700-775 tons/day during the year.

The annual reduction of EE production of sheet glass can reach up to $10 \%$ and depends on the load of production, but as a result of the repair and adjustment works carried out, the dynamics of deterioration of $\mathrm{EE}$ is slowed down.

The results of the processing of statistical daily data of the enterprise work showed the presence of only two significant factors for planning of specific fuel consumption for glass production, determination of EE of the enterprise for semi-annual and annual intervals.

The factors of "iron oxide content in glass" and "outside temperature" in the semi-annual interval have stable values and do not affect the determination of EE forecast values, therefore, are not taken into account in forecasting the specific consumption of natural gas of future periods. A nomogram has been developed, which determines the value of the specific consumption of natural gas for the production of sheet glass, taking into account the planned and reporting periods of future operation (6 months), when the planned average daily productivity and the time spent by the furnace were set.

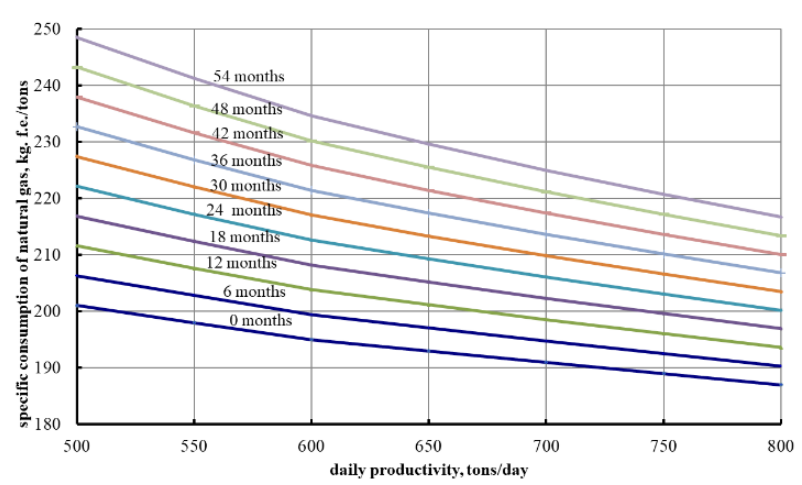

Fig. 2. Nomogram for determining the specific energy consumption of sheet glass production, taking into account the time spent by the furnace (without taking into account measures to improve energy efficiency).

A simplified method for estimating the rate of aging of the furnace lining and the wear of enclosing structures is proposed based on a one-factor model [8] of gas consumption from productivity by comparing the average daily values of specific gas consumption for the production of sheet glass at the same output volumes. In conditions of relatively stable annual values of feedstock characteristics and average annual outside temperature, it is possible to estimate the decrease in energy efficiency of a glass furnace caused by deterioration of the furnace lining and wear of the enclosing structures using onefactor models of the dependence of the total (specific) gas consumption on the volume of output:

$$
B_{s g c}=B_{\text {sgc.tech }}+B_{\text {sgc.const. }} / P, t \text { f.e./ units of prod (2) }
$$

Where:

$B_{\text {sgc.tech }}$ - technological specific gas consumption per product output, $\mathrm{t}$ f.e./units of prod;

$B_{\text {sgc.const. }}$ - conditional-constant component of gas consumption by technological installations, $\mathrm{t}$ f.e.

$P$ - volume of output per day, units of prod;

For glass production, energy resource costs associated with maintaining the working state of the furnace of the technological line form a technological conditional-constant component of fuel consumption (natural gas).

Table 2 shows the one-factor models developed over the five-year period of operation for dependence of specific gas consumption on sheet glass production [13]. The graphical interpretation of the models is shown in Figure 3.

Table 2. Specific gas consumption (sgc) models for sheet glass production.

\begin{tabular}{|c|c|c|c|}
\hline Year & Kind of model & $\begin{array}{c}\text { Bsgc.tech, } \\
\mathrm{t} \text { f.e./units }\end{array}$ & $\begin{array}{c}\text { Bsgc.const., } \\
\mathrm{t} \text { f.e. }\end{array}$ \\
\hline 2005 & $B s g c=0.11+69.11 / \mathrm{P}$ & 0.11 & 69.11 \\
\hline 2006 & $B s g c=0.07+101.8 / \mathrm{P}$ & 0.07 & 101.83 \\
\hline 2007 & $B s g c=0.09+85.95 / \mathrm{P}$ & 0.09 & 85.95 \\
\hline 2008 & Bsgc $=0.04+130 / \mathrm{P}$ & 0.04 & 130 \\
\hline 2009 & $B s g c=0,08+103.1 / \mathrm{P}$ & 0.08 & 103.1 \\
\hline
\end{tabular}

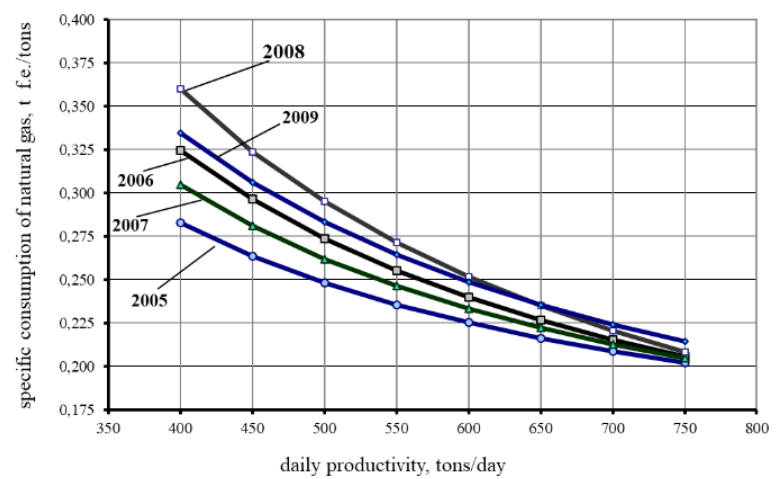

Fig. 3. Dynamics of specific gas consumption of sheet glass plant from 2005 to 2009.

As can be seen from the obtained models Bsgc $=F(P)$, in 2005, when sheet glass production was started at the design capacity, the specific gas consumption was minimal. In 2006, specific gas consumptions for sheet glass production increased. In 2007, as a result of repair works, debugging of the technological process and implementation of energy-saving measures, the values of 
specific gas consumption decreased relative to 2006, and in 2008 they increased again.

It has been found that at low loading of the sheet glass production line (400 tons/day), the reduction of EE due to burnout of the furnace lining and wear of the enclosing structures is more evident, since for such modes the influence of the conditional-constant component of the gas flow has more weight in the formation of the total specific flow rate. When the productivity of the process line increases, the influence of the conditional constant component of gas consumption, which is associated with maintaining the temperature regime of the furnace, decreases, as the technological component of gas consumption is growing [14]. The decrease in efficiency due to aging of the furnace lining at high productivity modes is less apparent (figure 4). For the production under study, it was found that during the five-year period the EE reduction was $18.4 \%$ with a minimum daily load of 400 tons/day on the production line.

With a capacity of 700 tons/day, the resulting change of EE (due to burning of the lining and wear of the enclosure structures of the furnace - hereinafter the coefficient of change of EE) is only $7.3 \%$ in a five-year period, or $1.8 \%$ in one year of operation, which correlates with the data of English specialists and scientific research of German scientists [6, 15]. It should also be noted that for the production under study, the main technological mode is a mode with a daily capacity of 760-775 t/day.

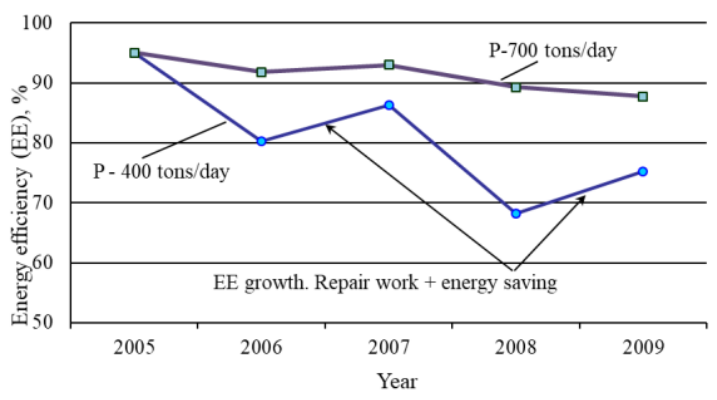

Fig. 4. Dynamics of changes of EE of sheet glass production for 2004-2009 at daily productivity of 400 and 700 tons/day.

\section{Research results}

Consider how ignoring the factors of "furnace lining aging and wear of enclosing structures," as well as "daily productivity" can lead to an error in the preparation of the application for natural gas. Thus, in 2009 for production the model has the following parameters: $B_{s g c}=0,08+103,1 / P, \mathrm{t}$ f.e./tons; . In the reporting year, the company operated with an average daily capacity of 550 tons/day with an actual achieved gas flow rate of $0.267 \mathrm{t}$ f.e./tons. This specific gas flow rate will be recorded as a statistical report and can be used in the calculation of the planned natural gas demand for the following year.

If the company plans to operate with an average daily capacity of 700 tons/day next year, then the planned gas demand (without the model) will be calculated using its statistical and reporting value of the specific gas consumption for output and the production plan for output.

The company will make a request for technological gas in the amount of: $\mathrm{B}_{\text {gas }}=0,267 \mathrm{t}$ f.e./tons 700 tons/day $=186,9 \mathrm{t}$ f.e./day or $68218.5 \mathrm{t}$ f.e/year, which in absolute terms is 59320.4 thousand $\mathrm{m}^{3}$. If we consider real dependence of specific gas consumption on production of sheet glass from the furnace productivity (table 2, figure 3 ), at the planned productivity of 700 t/day (growth of output volumes) the specific gas consumption will decrease to $0.227 \mathrm{t}$ f.e./tons, by analogy with the example $[16,17]$. Gas volume at a capacity of 700 tons/day will be 158.9 t f.e./day, or 57 $998.5 \mathrm{t}$ f.e/year, which in absolute terms will be 50433.5 thousand $\mathrm{m}^{3}$. In order to minimize the error in determining the planned demand for natural gas for the next year, the annual wear component of the furnace lining calculated according to the model should also be taken into account, that is, the predicted gas volume should be corrected taking into account the EE change factor of $1.8 \%$ according to the imputed constant component of the model. The total real value of the projected gas volume will be:

To minimize the error in determining the planned natural gas requirements for the next year should also be considered a component of the annual wear of the furnace lining, calculated by the model, in other words, the predicted volume of gas should be adjusted to the rate of change of $\mathrm{EE}+1.8 \%$ for the conditional constant component of the model. The final real value of the projected gas volume will be:

$$
\begin{aligned}
& B_{s g c}=0.08+(103.1 \cdot 1.018) / 700=0.23 t f . e . / \text { tons } \\
& B_{g a s}=0.23 t f . e / t \cdot 700 \text { tons } / \text { day }=161 t f . e / \text { day }
\end{aligned}
$$

or $58765 \mathrm{t}$ f.e/year, that in absolute expression makes 51100 thousand $\mathrm{m}^{3}$.

Thus, the error in the determination of demand for natural gas is estimated at $16 \%$ towards overstatement.

\section{Conclusions}

The production of sheet glass as a consumer of energy resources is characterized by the complex nature of the relationship between energy and technology: energy consumption is influenced by many technological factors. In order to identify and account for the factors forming the gas consumption mode, an information database has been formed, which includes 14 indicators characterizing the gas consumption mode. The studies carried out using correlation-regression analysis allowed to justify 4 factors determining the daily mode of gas consumption:

$P$ performance, $\mathrm{t} / \mathrm{day}$

$t_{o}$ outside temperature, ${ }^{\circ} \mathrm{C}$;

$F$ content of iron oxide in glass, $\%$;

$N$ number of days of furnace operation, day.

A nomogram has been developed, where, given the planned average daily productivity and time spent by the 
furnace, the value of the specific consumption of fuel (natural gas) for the production of sheet glass is determined taking into account the planned and reporting periods of future operation (6 months).

Invention proposes a simplified method of estimating the rate of aging of furnace lining and wear of enclosing structures on the basis of a single-factor model of gas consumption from productivity. It has been shown that ignoring the factors of "daily capacity" and "furnace lining burnout and wear of enclosing structures" can lead to an error in predicting the volume of gas consumption.

\section{References}

[1] Heat balance [Electronic resource], StaraGlass (2020). Available at:

https://www.staraglass.it/wpcontent/uploads/2019/11/Stara-Glass-HeatBalance-2020-r0.pdf

[2] S. Yaitskiy, L. Bragina, N. Yaitskiy, Features of the destruction of the refractory lining of glass melting furnaces in the production of sheet glass [Electronic resource] (2012) (in Russian). Available http://repository.kpi.kharkov.ua/handle/KhPIPress/10477

[3] V. Dzyuzer, V. Shvidkiy, Designing energy efficient glass furnaces (Moscow, Publishing house Tepltehnic, 340, 2009) (in Russian)

[4] L. Papko, Y. Pavlukevich, Refrigerators for glass furnaces (Minsk, BNTU, 95, 2008) (in Russian)

[5] R. Makarov, V. Tarbeev, E. Horosheva, Quality management of flat glass (float method) (Associations of construction universities, 152, 2004) (in Russian)

[6] GOST R 54201-2010, Resources saving, Production of domestic and container glass, Best available techniques for improving energy efficiency

[7] N.V. Hruntovich, A.A. Kapanski, D. Baczynski, G.V. Vagapov, O.V. Fedorov, Optimization of a variable frequency drive pump working on a water tower, E3S Web of Conferences 124, 05060, EDP Sciences (2019)

[8] N. Hruntovich, Y. Shenets, S. Zinovyeva, Development of methods for a comprehensive assessment of the effectiveness of energy conservation measures using one-factor mathematical models of specific fuel and energy consumption relative to the volume of output [Electronic resource], Energy efficiency (2013) (in Russian). Available at: http://energoeffekt.gov.by/downloads/publishing larchive journal/arhiv_journal_2013/En_11_201 $\underline{\text { 3.pdf }}$

[9] N. Hruntovich, D. Moroz, S. Zhukovec, Y. Shenets, Development of methodological support for diagnosing energy efficiency, Energy and Management (2017) (in Russian). Available at: $\quad$ http://www.webenergo.by/files/EiM/2017/EiM-1-2017.pdf
[10] O. Fedorov, Expeditious forecasting of power consumption, 2017 International Conference on Industrial Engineering, Applications and Manufacturing (ICIEAM), IEEE (2017)

[11] N. Hruntovich, D. Moroz, V. Sholonik, On the need to study the structure and patterns of functioning of regional gas supply systems, Energy strategy, 42-46 (2017) (in Russian)

[12] F. Baucke, G. Röth. Electrochemical mechanism of the oxygen bubble formation at the interface between oxidic melts and zirconium silicate refractories, Glastechnische Berichte 61, 5, 109118, 9 ref. (1988)

[13] R. Petuhova, N. Hruntovich, Y. Shenets, On the problems of energy efficiency management of sheet glass production [Electronic resource], Energy efficiency (2014) (in Russian). Available at:

http://energoeffekt.gov.by/downloads/publishing /archive journal/archive journal 2014/201403 energoeff.pdf

[14] N. Hruntovich, Y. Shenets, The influence of the structure of consumption of energy resources of the enterprise on the effectiveness of the implementation of energy saving measures [Electronic resource], Energy, Proceedings of universities and energy associations of the CIS, 58-66 (2014). Available at: https://energy.bntu.by/jour/issue/view/2/showTo $\underline{\mathrm{c}}$

[15] R.G.C. Beerkens, Energy Efficiency Benchmarking of Glass Furnaces /62 Conference on Glass Problem, 93-103 (2002)

[16] N. Hruntovich, D. Moroz, A. Kapanskij, S. Zhukovec, Y. Shenets, Using mathematical modeling methods to solve practical problems of energy efficiency assessment [Electronic resource], Energy and Management, 21-25 (2017). Available at: http://www.webenergo.by/files/EiM/2017/eim-3-2017.pdf

[17] Y.I. Gracheva, O.V Naumov, Estimation of Power Losses in Electric Devices of the Electrotechnical Complex, International Conference on Industrial Engineering, Applications and Manufacturing (ICIEAM), 6 (2019) 